\title{
Urban Metabolism Based on Emergy and Slack Based Model: A Case Study of Beijing, China
}

\author{
SONG Tao ${ }^{1,2,3}$, CAI Jianming ${ }^{1}$, XU Hui $^{3}$, DENG Yu ${ }^{1}$, NIU Fangqu ${ }^{1,4}$, YANG Zhenshan ${ }^{1}$, DU Shanshan ${ }^{5}$ \\ (1. Institute of Geographic Sciences and Natural Resources Research, Chinese Academy of Sciences, Beijing 100101, China; 2. Univer- \\ sity of Chinese Academy of Sciences, Beijing 100049, China; 3. Environmental Engineering, Division of Engineering and Applied Sci- \\ ences, Harvard University, Cambridge 02138, USA; 4. Key Laboratory of Regional Sustainable Development Modeling, Chinese \\ Academy of Sciences, Beijing 100101, China; 5. College of Arts \& Sciences, Beijing Union University, Beijing 100191, China)
}

\begin{abstract}
The key to studying urban sustainable development depends on quantifying stores, efficiencies of urban metabolisms and capturing urban metabolisms' mechanisms. This paper builds up the metabolic emergy account and quantifies some important concepts of emergy stores. Emphasis is placed on the urban metabolic model based on the slack based model (SBM) method to measure urban metabolic efficiencies. Urban metabolic mechanisms are discussed by using the regression method. By integrating these models, this paper analyzes the urban metabolic development in Beijing from 2001 to 2010. We conclude that the metabolic emergy stores of Beijing increased significantly from 2001 to 2010, with the emergy imported accounting for most of the increase. The metabolic efficiencies in Beijing have improved since the 2008 Olympic Games. The population, economic growth, industrial structures, and environmental governance positively affect the overall urban metabolism, while the land expansion, urbanization and environmentally technical levels hinder the improving of urban metabolic efficiencies. The SBM metabolic method and the regression model based on the emergy analysis provide insights into the urban metabolic efficiencies and the mechanism. They can promote to integrate such concepts into their sustainability analyses and policy decisions.
\end{abstract}

Keywords: emergy theory; urban metabolism; slack based model (SBM); Beijing Municipality; regression analysis

Citation: Song Tao, Cai Jianming, Xu Hui, Deng Yu, Niu Fangqu, Yang Zhenshan, Du Shanshan, 2015. Urban metabolism based on emergy and slack based model: A case study of Beijing, China. Chinese Geographical Science, 25(1): 113-123. doi: 10.1007/s11769014-0680-7

\section{Introduction}

The concept of urban metabolism came from a pioneering article on the metabolism of cities by Wolman (1965), in response to deteriorating air and water quality in American cities-issues still recognized today as threatening sustainable urban development (Kennedy et al., 2007). Wolman analyzed the metabolism of a hypothetical American city, quantifying the overall fluxes of energy, water, materials, and wastes into and out of an urban region of $1 \times 10^{6}$ people. Great deals of ambient particulate sampling studies have been conducted in a variety of cities by the research methods of material or energy flow analyses. These studies are typically of greater metropolitan areas, such as Sydney (Newman et al., 1996), Taiwan, China (Huang, 1998), Vienna (Hendriks et al., 2000), London (Chartered Institute of Wastes Management, 2002), Hamburg and a few other European cities (Hammer et al., 2003), Shanghai (Zhang et al., 2006a), Toronto (Forkes, 2007). In sum, an urban metabolism analysis is a means of quantifying the overall fluxes of energy, water, material, and wastes into and

Received date: 2013-07-29; accepted date: 2013-10-18

Foundation item: Under the auspices of National Natural Science Foundation of China (No. 41371008, 41101119), New Start Academic

Research Projects of Beijing Union University (No. ZK201201)

Corresponding author: DENG Yu. E-mail: dengy@igsnrr.ac.cn

(C) Science Press, Northeast Institute of Geography and Agroecology, CAS and Springer-Verlag Berlin Heidelberg 2015 
out of an urban region, somewhat analogous to human metabolism (Halla et al., 2003). It represents a holistic approach to urban planning, exploring the interactions among resource flows, urban transformation processes, waste streams and quality of life (Rotmans et al., 2000). Newman (1999) postulates that measuring urban material metabolism should include resource inputs/production and waste outputs, as well as other criteria such as livability, human amenity and health, employment, education, housing, accessibility and community. In a efficient urban metabolic system, resource consumption and waste generation are within the carrying capacity or assimilative capacity of the regional or global hinterland (Browne et al., 2009), as measured using material flow accounting (MFA), energy flows accounting or ecological footprint (EF) analysis (Zhang et al., 2009). By integrating the sum of all flows of available energy or material, the urban metabolic efficiency, ratio of output to input in urban metabolic systems can be calculated. The first comprehensive study on urban metabolism in Beijing was done in 2007 (Zhang and Yang, 2007a), and had analyzed Beijing's urban metabolic system using emergy synthesis to evaluate its environmental resources, economy, and environmental and economic relations with the regions outside the city. The later studies by Zhang et al. (2009) also pointed out the significance of reducing the reliance on external inputs of sources, energy and services.

On the basis of these reviews, most of the work on urban metabolism focuses on the accounting of the inputs and outputs of materials or energy flows of a specified society (Huang et al., 2006). However, the urban metabolic relationship between cities and their environments can not simply be viewed from linear accumulations of materials (Fischer-Kowalski and Haberl, 1997). Especially the efficiency analysis of urban metabolism is still deficient, and most of the studies focus on the quantization of urban material or energy input-output (Zhang and Yang, 2007b). In addition, more often than not, analyses neglect consideration of metabolic efficiencies based on incorporating the input excesses and output shortfalls. Research on the issue of urban metabolic efficiencies would go a long way towards the framework for both natural and social scientists to study the interrelations between urban systems and their environments. Further studies on the driving forces of urban metabolic efficiencies' differences would greatly enhance our understanding of urban metabolic system.
To address these issues, this paper creatively interprets urban metabolic efficiencies using 'emergy' (solar energy) and slack based model (SBM) analysis. It proposes to treat not only how a city's metabolism be measured but also what drive the metabolism. For these purposes, an index of urban metabolic efficiency is proposed, which provides insight into the urban metabolisms of resource and energy acquisition and use. This study focuses on the measurement of the urban metabolic efficiencies of a typical metropolis Beijing over the last decade. Implications for the driving forces are also presented in this study.

\section{Materials and Methods}

\subsection{Study area}

Beijing $\left(39^{\circ} 28^{\prime}-41^{\circ} 05^{\prime} \mathrm{N}, 115^{\circ} 25^{\prime}-117^{\circ} 35^{\prime} \mathrm{E}\right)$, is located in the northern part of the North China Plain and is the political, cultural and economic center of China. Beijing covers an area of $16410.54 \mathrm{~km}^{2}$ and consists of 14 districts and two counties (Yanqing and Miyun) (Fig. 1). As the second largest Chinese city by urban population after Shanghai, the total population in the study region is $1.96 \times$ $10^{7}(2010)$, nearly $86 \%\left(1.69 \times 10^{7}\right)$ of which live in urban areas. During the past decades, Beijing has experienced rapid economic growth. Beijing's gross domestic product (GDP) totaled $1.41 \times 10^{12}$ yuan (RMB) in 2010 , being almost 4.4 times of that in 2001, with tertiary industry accounting for $75 \%$ of its GDP in 2010 . Despite a great expansion of the tertiary industrial sectors in Beijing, more investments in urban infrastructure are needed for a better environment. Fog and haze conditions in Beijing serve as the best evidence of visibly metabolically unsustainable development due to the rampant urban growth. In addition, Beijing clearly belongs to the group of cities with a resource scarcity. The city has small reserves of coal, iron, and building materials. Most of the requirements for production and life depend on external inputs. Because of the city's vulnerability to interruptions in these resource flows, it is important to clearly understand Beijing's urban metabolism (Zhang et al., 2011).

\subsection{Data sources}

The data used in the analysis were derived from publically accessible reports prepared by the National Bureau of Statistics of China and Statistical Bureau of Beijing, such as China Statistical Yearbook 2001-2011 (National Bureau of Statistics of China, 2001-2011), China Urban 


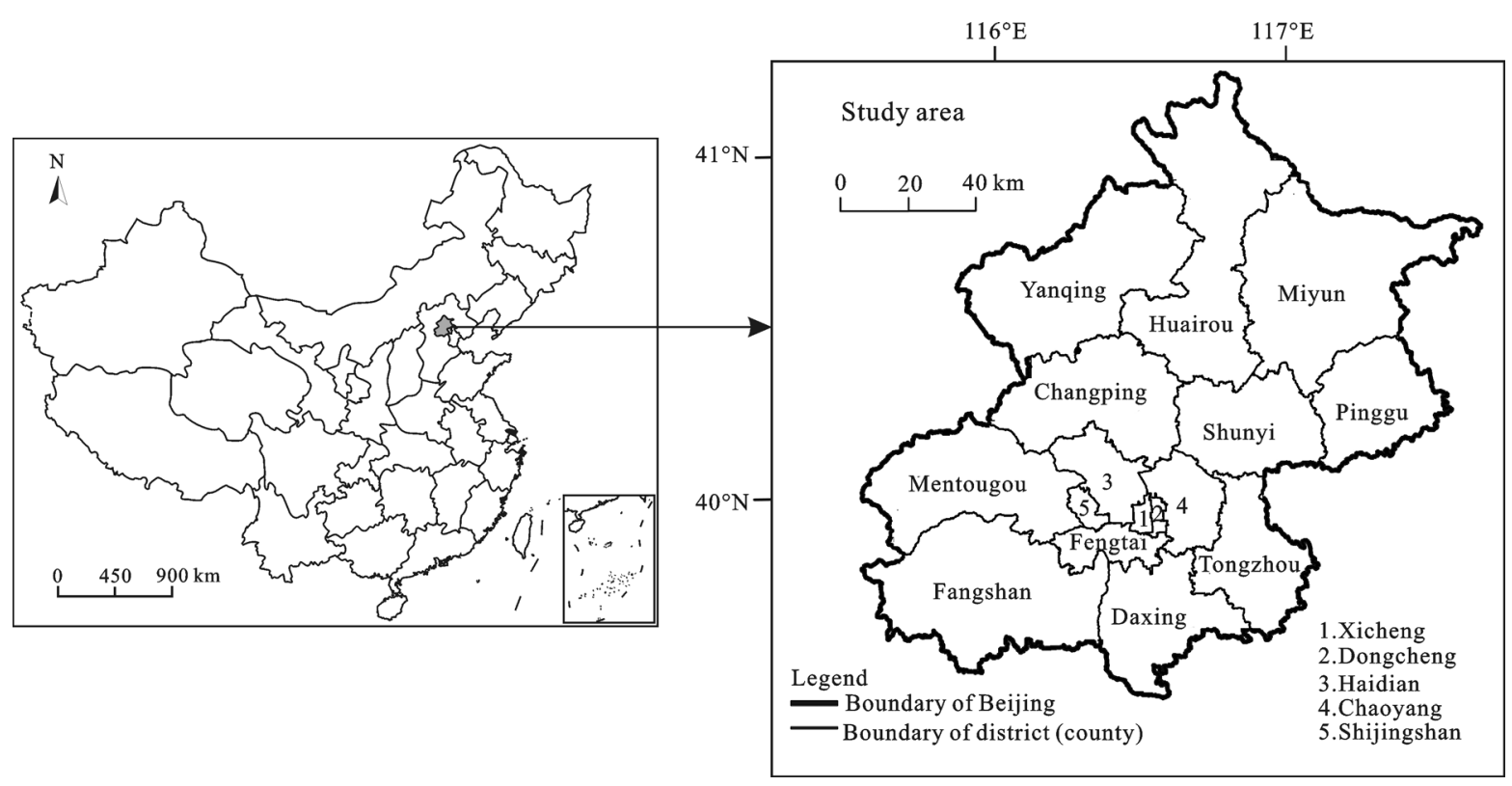

Fig. 1 Location of study area

Statistical Yearbook 2001-2011 (National Bureau of Statistics of China, 2001-2011), China Energy Statistical Yearbook 2001-2011 (National Bureau of Statistics of China, 2001-2011) and China Environmental Statistical Yearbook 2001-2011 (National Bureau of Statistics of China, 2001-2011). Detailed information on local resource production and consumption as well as imports and exports were collected from Beijing Statistical Yearbook 2001-2011 (Statistical Bureau of Beijing, 20012011). In terms of time span of this research, we chose the first decade of the 21 st century to compare changes of metabolic efficiencies and mechanisms in Beijing.

\subsection{Methods}

\subsubsection{Emergy analysis}

Odum originated emergy theory (Odum, 1971) to account for the quality of incoming energy and resources, i.e., for the environmental services supporting a process as well as for their convergence through a chain of energy and matter transformations in both space and time. By definition, emergy is the amount of energy of one type (usually solar) that is directly or indirectly required to provide a given flow or storage of energy or matter. The units of emergy are emjoules (abbreviated eJ) to distinguish them from energy joules (abbreviated J). The solar emergy required generating a unit flow or storage of available energy is called solar transformity and is expressed as solar emergy joules per joule of output flow $(\mathrm{seJ} / \mathrm{J})$. The transformity of solar radiation is as- sumed equal to one by definition (1.0 seJ/J) (Ulgiati and Brown, 2009). By using the tool of transformities, the emergy analysis provides a single unit of measurement that can account for all material, energy, and monetary flows between the urban system and its surrounding environment (Odum, 1988). Detailed information can be found from Odum (1996), Odum et al. (2000), Huang and Chen (2005), Zhang et al. (2009).

Emergy analysis has been applied to study the socioeconomic-environmental metabolism of many cities in recent years, e.g., Hong Kong, China (Lan and Odum, 1994), Sydney, Australia (Newman, 1999), Taipei, Taiwan Province, China (Huang, 1998), Toronto, Canada (Sahely et al., 2003), Zhongshan, Guangdong Province, China (Lu et al., 2003), Macao, China (Lei and Wang, 2008). These studies provide valuable reference for integrating urban systems' metabolic health assessment with emergy analysis (Su, 2010). However, these studies have placed emphasis on the linear accumulation values of material flows in the city systems, and lack further research on the urban metabolism efficiency based on the input-output perspective, especially considering amounts of waster emergy. In this paper, to better measure the urban metabolic efficiencies, a typical framework of emergy items describing an urban metabolic system is shown in Table 1, which treats a comprehensive portfolio of not only renewable and non-renewable resources' emergy inputs and products, import and export products and services, but also waste outputs. 
Table 1 Emergy items of urban metabolism and transformity

\begin{tabular}{|c|c|c|c|c|}
\hline Emergy item & Item & Unit & Transformity (seJ) & Reference of transformity \\
\hline \multirow[t]{7}{*}{ Renewable emergy $(R)$} & Sunlight & $\mathrm{J}$ & 1 & Odum, 1996 \\
\hline & Wind, Kinetic & $\mathrm{J}$ & $2.45 \times 10^{3}$ & Odum et al., 2000 \\
\hline & Rainfall (chemical) & $\mathrm{J}$ & $3.05 \times 10^{4}$ & Odum et al., 2000 \\
\hline & Rainfall (geopotential) & $\mathrm{J}$ & $4.70 \times 10^{4}$ & Odum et al., 2000 \\
\hline & Waves & $\mathrm{J}$ & $2.59 \times 10^{4}$ & Odum,1996 \\
\hline & Earth cycle & $\mathrm{J}$ & $5.80 \times 10^{4}$ & Odum et al., 2000 \\
\hline & Water & $\mathrm{J}$ & $3.05 \times 10^{4}$ & Odum et al., 2000 \\
\hline \multirow{3}{*}{$\begin{array}{l}\text { Indigenous renewable } \\
\text { emergy }(I R)\end{array}$} & Crop & $\mathrm{g}$ & $2.43 \times 10^{11}$ & Odum, 1996 \\
\hline & Livestock & $\mathrm{g}$ & $1.49 \times 10^{11}$ & Odum, 1996 \\
\hline & Fishery & $\mathrm{g}$ & $1.80 \times 10^{10}$ & Odum, 1996 \\
\hline \multirow{11}{*}{$\begin{array}{c}\text { Locally } \\
\text { non-renewable } \\
\text { Emergy }(N)\end{array}$} & Cement & $\mathrm{g}$ & $1.00 \times 10^{9}$ & Odum, 1996 \\
\hline & Topsoil loss & $\mathrm{t}$ & $1.71 \times 10^{3}$ & Huang and Chen, 2005 \\
\hline & Electricity & $\mathrm{J}$ & $1.60 \times 10^{5}$ & Odum, 1996 \\
\hline & Steel & $\mathrm{g}$ & $1.80 \times 10^{9}$ & Odum, 1996 \\
\hline & Raw coal & $\mathrm{J}$ & $4.00 \times 10^{4}$ & Odum, 1996 \\
\hline & Crude oil & $\mathrm{J}$ & $5.04 \times 10^{4}$ & Odum, 1996 \\
\hline & Gasoline & $\mathrm{J}$ & $1.11 \times 10^{5}$ & Odum, 1996 \\
\hline & Diesel fuel & $\mathrm{J}$ & $1.11 \times 10$ & Odum, 1996 \\
\hline & Liquid petroleum gas & $\mathrm{J}$ & $4.80 \times 10^{4}$ & Odum, 1996 \\
\hline & Fuels oil & $\mathrm{J}$ & $6.25 \times 10^{4}$ & Odum et al., 2000 \\
\hline & Fertilizer & $\mathrm{t}$ & $8.28 \times 10^{6}$ & Ascione et al., 2009 \\
\hline \multirow[t]{4}{*}{ Imported emergy (IM) } & Goods & $\$(U S D)$ & $9.37 \times 10^{12}$ & Jiang et al., 2007 \\
\hline & Service & $\$(U S D)$ & $9.37 \times 10^{12}$ & Jiang et al., 2007 \\
\hline & Fuel & $\mathrm{J}$ & $8.55 \times 10^{4}$ & Odum, 1996 \\
\hline & Tourism income & \$(USD) & $1.66 \times 10^{12}$ & Brown and Ulgiati, 2002 \\
\hline \multirow[t]{2}{*}{ Exported emergy $(E X)$} & Goods & $\$(\mathrm{RMB})$ & $6.34 \times 10^{12}$ & Jiang et al., 2007 \\
\hline & Service & $\$(\mathrm{RMB})$ & $6.34 \times 10^{12}$ & Jiang et al., 2007 \\
\hline \multirow[t]{3}{*}{ Waste emergy $(W)$} & Rubbish & g & $1.80 \times 10^{9}$ & Huang and Hsu, 2003 \\
\hline & Sewage & $\mathrm{g}$ & $6.66 \times 10^{8}$ & Huang and Hsu, 2003 \\
\hline & Emission & $\mathrm{g}$ & $6.66 \times 10^{8}$ & Huang and Hsu, 2003 \\
\hline
\end{tabular}

An important indicator underlying the measurement of emergy flows throughout an urban metabolic system is the total amount of emergy consumed by the city within a year $(U)$, which states the total net emergy throughput without exports and wastes, consisting of four parts: renewable emergy $(R)$, indigenous renewable emergy $(I R)$, non-renewable emergy $(N)$ and imported emergy $(I M)$. Another indicator with the same significance is the total emergy with exports and wastes $(U s)$, which expresses emergy sum of import and export, input and output. In addition, the proportion of imported (IM) and exported emergy values $(E X)$ accounting for the total emergy with exports and wastes $(U s)$, called $E U$, elaborates system's dependence on external resources and energy. The higher the $E U$, the more vulnerable urban metabolisms are.

\subsubsection{Urban metabolic model based on SBM}

Since the innovative work by Charnes et al. (1978), studies in Data Envelopment Analysis (DEA) have been extensively conducted (Cooper et al., 2000; Zhou et al., 2008), whose main objective is to measure the efficiency of a Decision Making Unit (DMU) by a scalar measure ranging between zero (the worst) and one (the best) (Tone, 2001). Regional sustainable problems can be modeled and addressed by this systematic analysis method, considering the economic and environmental 
inputs and outputs (Mandal and Madheswaran, 2010; Oggioni et al., 2011). Especially with the enhancement of environmental protection consciousness, some environmental issues such as air pollution and hazardous waste have been widely recognized as a social issue. So, how to correctly measure environmental efficiency considering undesirable output becomes a hot topic (Fare and Grosskopf, 2004). Fortunately, a slack-based efficiency measure (SBM) on the basis of environmental DEA technology was proposed to solve the issue of assessment efficiency of undesirable output (Fare et al., 2007). SBM model based on the DEA has recently become a popular method in measuring integral efficiency and has made great contributions to estimating integrated the efficiency of regional development (Zhou et al., 2013). Previous scholars did a lot of empirical researches on the efficiency of industries, or regional environments, but lacked deep discussion on the urban metabolic efficiencies by using the SBM.

In this section, we develop the urban metabolic model based on the SBM (Tone, 2004).

$$
\begin{aligned}
p= & \left\{\left(x, y^{\mathrm{g}}, y^{\mathrm{b}}\right) \mid x \geq X \lambda,\right. \\
& \left.y^{\mathrm{g}} \leq Y^{\mathrm{g}} \lambda, \quad y^{\mathrm{b}} \geq Y^{\mathrm{b}}, \quad \lambda \geq 0\right\}
\end{aligned}
$$

where $P$ is $D M U$ of the production system; The vectors of input, desirable output and undesirable output in the production system are expressed as $x, y^{\mathrm{g}}, y^{\mathrm{b}} ; \lambda$ is a weight vector; $X, Y^{\mathrm{g}}, Y^{\mathrm{b}}$ are matrices of input, desirable output and undesirable output, respectively.

By integrating pure environmental inefficiency and economic inefficiency, the urban metabolic efficiency can be measred by the following extended slack-based efficiency method (SBM) with the extended undesirable outputs as follows:

$$
\begin{gathered}
\rho=\min \frac{1-(1 / m) \sum_{i=1}^{m} A S_{i}^{-} / x_{i 0}}{1+\frac{1}{S_{1}+S_{2}}\left(\sum_{r=1}^{S_{1}} S_{r}^{\mathrm{g}} / y_{r 0}^{\mathrm{g}}+\sum_{r=1}^{S_{2}} S_{r}^{\mathrm{b}} / y_{r 0}^{\mathrm{b}}\right)} \\
\text { s.t }: x_{0}=X \lambda+S^{-} ; y_{0}^{\mathrm{g}}=Y^{\mathrm{g}} \lambda-S^{\mathrm{g}} ; y_{0}^{\mathrm{b}}=Y^{\mathrm{b}} \lambda+S^{\mathrm{b}} ; \\
\lambda \geq 0, S^{-} \geq 0, S^{\mathrm{g}} \geq 0, S^{\mathrm{b}} \geq 0
\end{gathered}
$$

where each city has $m$ inputs, $S_{1}$ is good outputs, and $S_{2}$ is bad outputs; $i$ is a input unit while $r$ is a output unit in a city; $X, Y^{\mathrm{g}}, Y^{\mathrm{b}}$ are matrices of input, desirable output and undesirable output, as mentioned above. The vectors
$S^{-}, S^{\mathrm{g}}$, and $S^{\mathrm{b}}$ correspond to slacks in inputs, desirable outputs, and undesirable outputs, respectively. The $x_{i 0}$, $y_{r 0}^{\mathrm{g}}, y_{r 0}^{\mathrm{b}}$ represent the input, desirable output and undesirable output in the frontier unit 0 . The computed value of $\rho$ is the urban metabolic efficiency, illustrating the overall technical efficiency score for a city with the inclusion of undesirable outputs ( $\mathrm{Li}$ and $\mathrm{Hu}, 2012$ ). Only if $\rho=1$, the corresponding DMU is effective; i.e., $S^{\mathrm{g}}=0$, $S^{\mathrm{b}}=0, S^{-}=0$ (maximum desirable outputs and minimum undesirable slack outputs) are efficient. If $0<\rho<1$, the DMU is ineffective, indicating that the evaluation unit is inefficient.

$x_{0} \leftarrow x-S^{-} ; y_{0}^{\mathrm{g}} \leftarrow y^{\mathrm{g}}+S^{\mathrm{g}} ; y_{0}^{\mathrm{b}} \leftarrow y^{\mathrm{b}}-S^{\mathrm{b}}$

where the inefficient DMU $\left(x, y^{\mathrm{g}}, y^{\mathrm{b}}\right)$ and its projection $\operatorname{DMU}_{0}\left(x_{0}, y_{0}{ }^{\mathrm{g}}, y_{0}{ }^{\mathrm{b}}\right)$ in the frontiers are specified as Equation (3). The DMU can be improved and become efficient by reducing the surplus inputs $S$, increasing the desirable outputs $S^{\mathrm{g}}$, and reducing the excesses in undesirable outputs $S^{\mathrm{b}}$.

Note that the set of constraints on undesirable outputs in Equation (3) can guarantee that DMU has now been an efficient practitioner in pure urban metabolic performance. Therefore, Equation (2) can be used to evaluate the metabolic inefficiency of DMU by a slacksbased efficiency measure $\rho$ after its pollutants are adjusted to their minimum levels (Zhou et al., 2006).

Based on the emergy analysis, the desirable outputs $\left(Y^{\mathrm{g}}\right)$ and undesirable outputs $\left(Y^{\mathrm{b}}\right)$ come from the gross domestic product (GDP) and the emergy of wastes $(W)$, which include sewages, emissions and solid wastes, respectively. The input data come from the emergy imported $(I M)$ and the locally non-renewable emergy $(N)$, which serve as the main driving forces of emergy development.

\subsubsection{Mechanism of urban metabolism based on least squares regression}

The urban metabolic efficiency based on SBM is directly dependent on the inputs and outputs selected, but also affected by the economic growth, industrial structures, technical improvements, urbanization, environmental governance, environmental protection investments, etc. (Selden and Song, 1994). In this paper, seven factors are chosen to frame the mechanism of urban metabolisms, such as the economic growth, industrial structures, urbanization, land expansion, population, environmentally technical levels and the environmental 
governance.

Least-squares regression is a method for finding a line that summarizes the relationship between variables, which has been widely used to quantify the mechanism of a system (Braak and Juggins, 1993). After the standardization of all variables, the mechanism model of urban metabolic efficiency $(M U)$ is built as follows:

$$
\begin{aligned}
M U= & C+\beta_{1} E_{i}+\beta_{2} I_{i}+\beta_{3} U_{i}+\beta_{4} L_{i}+ \\
& \beta_{5} P_{i}+\beta_{6} T_{i}+\beta_{7} G_{i}+\varepsilon_{i}
\end{aligned}
$$

where $C$ is the constant term of the regression; $\beta_{1}-\beta_{7}$ are regression coefficients of the independent variables; $i$ is the number of DMU; $\varepsilon_{i}$ is the error term of the regression equation; $E_{i}$ is per capita GDP (10 000 yuan/people) in the $i$ th unit, representing the economic grwoth; $I_{i}$ is percentage of tertiary industry accounted for GDP (\%) in the $i$ th unit, representing the industrial structure; $U_{i}$ is proportion of the urban population (\%) in the $i$ th unit, representing the urbanization; $L_{i}$ is proportion of construction land (\%) in the $i$ th unit, representing the land expansion; $P_{i}$ is population density (peo$\mathrm{ple} / \mathrm{km}^{2}$ ) in the $i$ th unit, representing the population growth; $T_{i}$ is standard amount of energy consumption per 10000 yuan GDP (t/10000 yuan) in the $i$ th unit, representing the environmentally technical level; $G_{i}$ is percentage of investments in the treatment of industrial pollution accounted for GDP (\%) in the $i$ th unit, illustrating the environmental governance.

\section{Results}

\subsection{Stores of urban emergy metabolic system}

Based on the metabolic systems of Beijing from 2001 to 2010, the total amounts of emergy consumed per year by Beijing $(U)$ are presented in Fig. 2. The $U$ of Beijing has grown very significantly in the period, with $3.62 \times 10^{24}$ seJ in 2010, almost four times in 2001. As to the items of $U$, the emergy imported (IM) has been the main driver of rising emergy consumption. The locally nonrenewable emergy $(N)$ has a large base and a steady growth since 2001, while the renewable emergy ( $R$ and $I R$ ) have such small bases that they are not visible in Fig. 2, so their contribution can be considered negligible. Considering the overall contribution of imported emergy (IM), the emergy footprint of Beijing is expanding substantially.

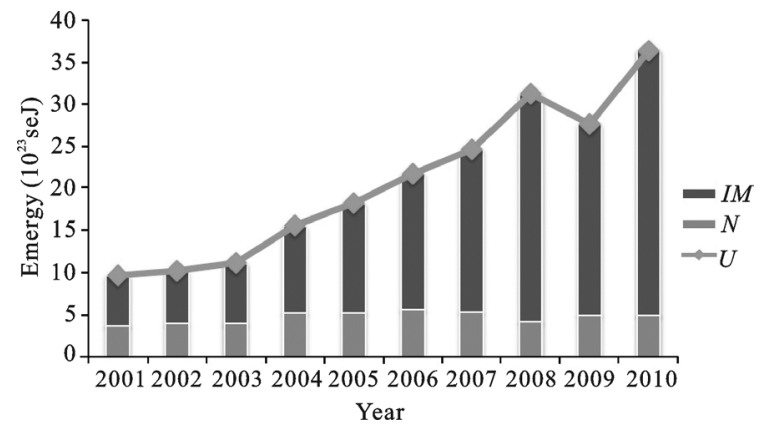

Fig. 2 Emergy performances and items of total amounts of emergy $(U)$ in Beijing from 2001 to 2010. IM, imported emergy; $N$, non-renewable emergy

The emergy external intensity $(E U)$ can indicate the degree of cities' dependences on external regions. A high $E U$ value means that more external resources, energy, and services would be imported, consumed and exported to satisfy the demand of urban development. As shown in Fig. 3, during the 10-year study period, Beijing's $E U$ increased from $67.4 \%$ in 2001 to $88 \%$ in 2010. The growth of values indicates that Beijing is more vulnerable in view of its highly dependence on external resources and energy (Peng et al., 2011).

\subsection{Urban metabolic efficiencies based on SBM}

We apply the slacks-based efficiency measure to study urban metabolic efficiencies of Beijing from 2001 to 2010. Two inputs, one desirable output and one undesirable output, are employed here. Table 2 shows the summary statistics of data collected.

It can be observed from Table 3 that Beijing has achieved a $\rho$ value of 1 in 2001, 2006, 2008 and 2010, which means that Beijing could be taken as fully an efficient urban metabolic practitioner in both environmental and economic performances in the four years.

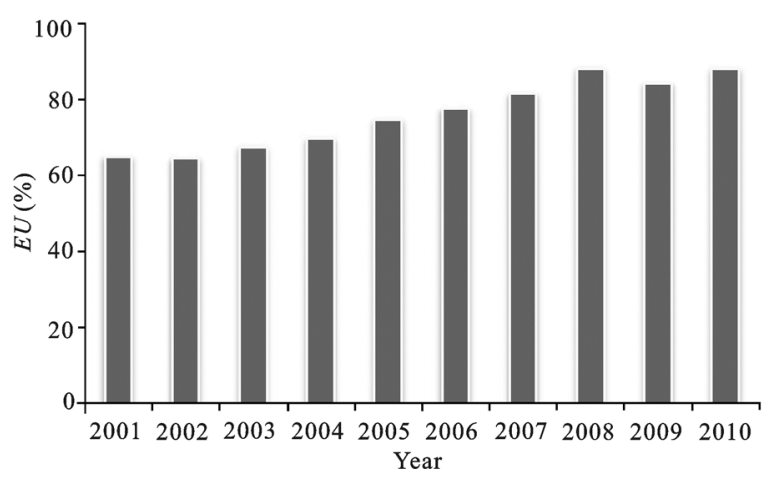

Fig. 3 Emergy external intensity index $(E U)$ in Beijing from 2001 to 2010 
Table 2 Statistics on input/output data

\begin{tabular}{ccccc}
\hline & $\begin{array}{c}I M \\
\left(10^{23} \mathrm{seJ}\right)\end{array}$ & $\begin{array}{c}N \\
\left(10^{23} \mathrm{seJ}\right)\end{array}$ & $\begin{array}{c}\text { GDP } \\
(10000 \text { yuan })\end{array}$ & $\begin{array}{c}W \\
\left(10^{22} \mathrm{seJ}\right)\end{array}$ \\
\hline Maximum & 31.26 & 5.55 & 14113.61 & 1.59 \\
Minimum & 5.91 & 3.72 & 3710.50 & 1.35 \\
Average & 15.82 & 4.70 & 8119.32 & 1.46 \\
$\begin{array}{l}\text { Standard } \\
\text { deviation }\end{array}$ & 8.49 & 0.62 & 3363.92 & 0.07 \\
\hline
\end{tabular}

Notes: $W$, emergy of wastes; $I M$, emergy imported; $N$, locally nonrenewable emergy

For years with $\rho$ value less than 1 , their inefficiencies mainly arise from excess usage of certain non-renewable resource and imported inputs, excess production of undesirable outputs-wastes or low production of desirable output, which can be identified and estimated by the slack variables $S^{-}$and $S^{\mathrm{g}}$ and $S^{\mathrm{b}}$ in Table 3 (Zhou et al., 2006). Interestingly, the increased frequency of $\rho$ value 1 since 2008 illustrates that these environmentalfriendly initiatives before the Olympics of 2008 (e.g., the closure of polluting factories) had laid a good foundation for Beijing's urban metabolism.

\subsection{Mechanism of urban metabolism}

The least squares regression method, a linear function with Beijing's urban efficiency values as the dependent variable, is employed for the solution of urban metabolic mechanism. The significances of variables based on the regression are shown in Table 4, the population $(P)$, economic growth $(E)$, industrial structures $(I)$ and environmental governance $(G)$ are positively related to

Table 3 Urban metabolic efficiencies of Beijing from 2001 to 2010

\begin{tabular}{cccccc}
\hline$D M U$ & $\rho$ & $\begin{array}{c}S^{-}(I M, \\
\left.10^{23} \mathrm{seJ}\right)\end{array}$ & $\begin{array}{c}S^{-}(N, \\
\left.10^{23} \mathrm{seJ}\right)\end{array}$ & $\begin{array}{c}S^{\mathrm{g}}(\mathrm{GDP}, \\
\left.10^{4} \text { yuan }\right)\end{array}$ & $\begin{array}{c}S^{\mathrm{b}}(W, \\
\left.10^{21} \mathrm{seJ}\right)\end{array}$ \\
\hline 2010 & 1 & 0 & 0 & 0 & 0 \\
2009 & 0.90 & 1.22 & 0.10 & 1726.0909 & 0 \\
2008 & 1 & 0 & 0 & 0 & 0 \\
2007 & 0.79 & 4.29 & 0.32 & 4419.7735 & 0 \\
2006 & 1 & 0 & 0 & 0 & 0 \\
2005 & 0.62 & 0 & 0.02 & 7929.1964 & 1.04 \\
2004 & 0.57 & 1.12 & 0 & 8845.7362 & 0.21 \\
2003 & 0.90 & 0 & 0 & 1082.0057 & 0 \\
2002 & 0.84 & 3.13 & 0 & 1622.5284 & 0 \\
2001 & 1 & 0 & 0 & 0 & 0 \\
\hline
\end{tabular}

Notes: $S^{-}(I M)$, slacks of inputs from emergy imported; $S^{-}(N)$, slacks of inputs from locally non-renewable emergy; $S^{\mathrm{g}}$ (GDP), slacks of desirable outputs from GDP; $S^{b}(W)$, slacks of undesirable outputs from wasted emergy the metabolic efficiency in Beijing, where the population is very significant with the significance level above $5 \%$; while others are significant with the significance level above $10 \%$. Negative factors related include the land expansion $(L)$, urbanization $(U)$ and environmentally technical levels $(T)$, in which the land expansion is the most negatively significant related to the metabolic efficiency in Beijing.

The standardization values of variables are based on the time-series data of Beijing from 2001 to 2010 in Fig. 4. From 2001 to 2010, the economic growth, urbanization, population, land expansion and tertiary industry in Beijing had been gradually growing. The percentage of tertiary industry accounted for GDP declined a little since 2008, possibly due to the rapid development of modern industry (Zhang et al., 2006b). It had been fluctuating that the percentage of investments in the treatment of industrial pollution accounted for GDP, illustrating that the environmental governance should be put more emphasis on. Finally, with the improvement of energy technologies, the energy consumption per 10000 yuan GDP in Beijing had been decling since 2001.

The mechanism of urban metabolism in Beijing will be detailed in this part. First, With the rapid development of urban metabolism system in Beijing, Beijing' per capita GDP grew from 26800 yuan/person in 2001 to 71900 yuan/person in 2010, whose standardization values are shown in Fig. 4. Beijing's per capita GDP has a significant positive correlation with the urban metabolic efficiency, whose coefficient reaching 0.87 , illustrating that the economic agglomeration in Beijing affects greatly the urban overall metabolism. Second, in 2001, the proportion of tertiary industry in GDP arrived at $67 \%$, then grew to $70 \%$ in 2006 and finally stabilized at above $75 \%$ since 2008, witnessing Beijing's serviceoriented industrial structure. The optimization of the industrial structure also plays a driving role in Beijing's metabolic efficiencies, but its coefficient is just 0.03 , which goes a long way towards improving urban metabolic performance. Third, since 2001 to 2010, the construction lands in Beijing increased from $2924 \mathrm{~km}^{2}$ to $3511 \mathrm{~km}^{2}$, whose share in the proportion of land also increased from $17.9 \%$ to $21.4 \%$. With the growth of constuction lands since 2000, the proportion of construction lands and metabolic efficiencies in Beijing show a strongly significant negative correlation. This information is useful since it provides guidance for the 
government to reduce the expansion of construction lands, which contribute to the inefficiency of urban metabolic performances. Fourth, population density in Beijing increased to 1195 people $/ \mathrm{km}^{2}$ in 2010 , whereas 844 people $/ \mathrm{km}^{2}$ in 2001 . The population growth attributes to most of the metabolic efficiency increase, with the coefficient of 0.996 . It illustrates that although stores of urban emergy metabolisms increase with population growth, urban metabolic efficiencies improve as well. This may be attributable to a returns-to-scale effect of urban metabolic capacity. Moreover, the environmental governance has a positive impact on the metabolic efficiency. However, investments in the treatment of pollution had declined since 2005 and dropped to $3.44 \times 10^{8}$ yuan in 2010 , from $4.78 \times 10^{8}$ yuan in 2001 . It illustrates that the environmental governance should be strengthened to improve the metabolic efficiency. The urbanization rate (the proportion of the urban population accounted for the resident population) increased to $86 \%$ in 2010 from 78.1\% in 2001, which means that Beijing is currently one of the China's most developed urbanization region (Chang et al., 2013). Last but not least, the energy consumption was $1.14 \mathrm{t}$ of standard coal per 10000 yuan GDP in Beijing in 2001, and dropped to 0.49 in 2010. However, the correlation between the urbanization and metabolic efficiencies is not significant, as well as the environmentally technical level and all of them should be further tested.

Table 4 Significances of variables based on regression

\begin{tabular}{|c|c|c|c|c|c|}
\hline Variable & Name & Coefficient & SE & $t$-statistic & Significance \\
\hline$E$ & Economic growth & 0.874751 & 2.798795 & 0.312546 & $*$ \\
\hline$I$ & Industrial structure & 0.032036 & 0.676636 & 0.047345 & $*$ \\
\hline$U$ & Urbanization & -0.049616 & 1.251421 & -0.039648 & \\
\hline$L$ & Land expansion & -1.624742 & 1.939331 & -0.837785 & $* *$ \\
\hline$P$ & Population density & 0.966252 & 0.935432 & 1.032948 & ** \\
\hline$T$ & Environmentally technical level & -0.098684 & 2.091802 & -0.047176 & \\
\hline$G$ & Environmental governance & 0.240318 & 1.198311 & 0.200547 & $*$ \\
\hline $\mathrm{C}$ & Constant & 0.862885 & 2.419592 & 0.356624 & \\
\hline
\end{tabular}

Notes: $* *, *$ denote significant levels at $5 \%$ and $10 \%$, respectively; the rest did not pass $10 \%$ test

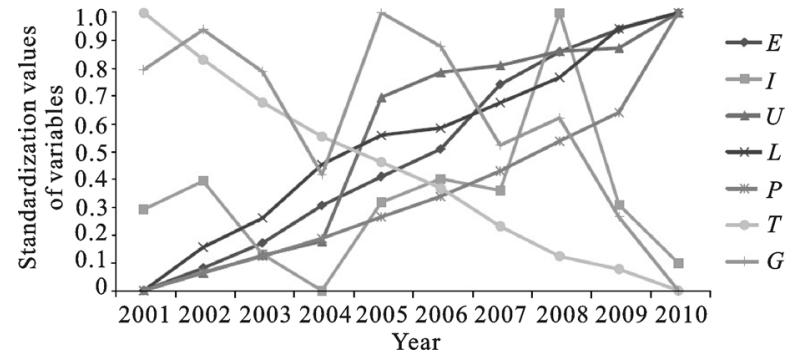

Fig. 4 Standardization values of all mechanism variables in Beijing from 2001 to 2010. E, economic growth; I, industrial structures; $U$, urbanization; $L$, land expansion; $P$, population density; $T$, environmentally technical levels; $G$, environmental governance

\section{Conclusions and Suggestions}

Emergy analysis and slack based DEA model are both significant tools for understanding urban metabolisms. Instead of developing urban metabolic model simply capturing linear accumulations and flows of urban materials, this research extends an urban metabolic emergy system with incorporating the SBM model and the re- gression analysis. The empirical analysis of emergy flows presented here for Beijing is based on periodically available statistical data sources. We started by establishing urban metabolic emergy accounts, including the renewable emergy, non-renewable emergy, imported emergy, exported emergy, and wasted emergy. After that, we quantified the metabolic efficiency based on incorporating the input excesses and output shortfalls using SBM model, and measured the mechanism of urban metabolism by regression model.

Several key conclusions can be drawn from this paper: 1) The metabolic emergy stores of Beijing increased significantly between 2001 and 2010 , from $9.67 \times 10^{23}$ seJ in 2001 to $3.62 \times 10^{24} \mathrm{seJ}$ in 2010 . The imported emergy (IM) accounted for more than half of the increase, followed by locally non-renewable emergy $(N)$, with the remainder attributed to the growth of renewable emergy ( $R$ and $I R$ ). 2) Beijing had the highest metabolic efficiencies in 2001, 2006, 2008 and 2010. Interestingly, since the Olympics of 2008, the efficiencies were getting steady and better, perhaps due to environmental- 
friendly initiatives taken by the government. 3) Beijing's population density $(P)$ and per capita GDP $(E)$ have significant positive correlations with urban metabolic efficiencies, illustrating that the economic and population agglomeration in Beijing affect greatly the urban overall metabolism. The environmental governance and the industrial instructure improvement positively drive the growth of metabolic efficiencies. In addition, the expansion of construction lands contributes to the inefficiency of urban metabolic performances.

Based on the conclusions, the strategies that we recommended include improving overall efficiency at production and consumption of nonrenewable resources. Secondly, reliance on renewable resources, instead of nonrenewable and imported resources, needs to be explicitly considered in Beijing's urban programs for urban metabolic improvement. Thirdly, improved management in imported services, goods and fuels, such as alternative energy import policy, are vital for Beijing to obtain the goal of metropolitan sustainable development Furthermore, it is important that decision makers should be given the analysis of urban metabolic performances to deveop technologies and policies that diversify metropolitan renewable resource and energy suppplies and stimulate metabolic efficiency improvements while mitigating the undesirable outputs from urban metabolic development.

These synthetic methods, including urban metabolic emergy system, urban metabolic model based on SBM, metabolic mechanism based on regression, emphasize the importance of understanding the key aspects that determine the urban metabolic performances and provides scientific basis for appraising urban metabolic stores, efficiencies and mechanisms. However, more future work should be done to better depict urban metabolic systems. First, metropolises, such as Beijing, are vulnerable to urban desertification and over dependence on external resources, so it is necessary to capture the urban emergy footprints of metabolic systems in future, which is an important spatial aspect of urban metabolisms. Second, studies should go further in improving drawbacks of metabolic models, such as bad independence of the indicators, and insufficient comprehensive quantization, in current models. Synthesis of the existing information will be a crucial first step. Cross-cutting field research and integrated, multidisciplinary simulations will be necessary. In last, planning and manage- ment for urban sustainable metabolisms is not completed in an integrated manner. As a consequence, detailed policy framework is still not accounted in decision-making process, and scholars should put more emphasis on the policy-oriented metabolic studies.

\section{References}

Ascione M, Campanella L, Cherubini F et al., 2009. Environmental driving forces of urban growth and development. Landscape and Urban Planning, 93(3): 238-249. doi: 10.1016/ j.landurbplan.2009.07.011

Braak C J F, Juggins S, 1993. Weighted averaging partial least squares regression (WA-PLS): An improved method for reconstructing environmental variables from species assemblages. Hydrobiologia, 269(1): 485-502. doi: 10.1007/BF000 28046

Brown M T, Ulgiati S, 2002. Emergy evaluations and environmental loading of electricity production systems. Journal of Cleaner Production, 10(4): 321-334. doi: 10.1016/S09596526(01)00043-9

Browne D, O'Regan B, Moles R, 2009. Assessment of total urban metabolism and metabolic inefficiency in an Irish city-region. Waste Management, 29(10): 2765-2771. doi: 10.1016/j.wasman. 2009.05.008

Chang Qing, Li Shuangcheng, Wang Yanglin et al., 2013. Spatial process of green infrastructure changes associated with rapid urbanization in Shenzhen, China. Chinese Geographical Science, 23(1): 113-128. doi: 10.1007/s11769-012-0568-3

Charnes A, Cooper W W, Rhodes E, 1978. Measuring the efficiency of decision-making-units. European Journal of Operational Research, 2(6): 429-444. doi: 10.1016/0377-2217(78) 90138-8

Chartered Institute of Wastes Management, 2002. A Resource Flow and Ecological Footprint Analysis of Greater London. London: Best Foot Forward.

Cooper W W, Seiford L M, Tone K, 2000. Data Envelopment Analysis: A Comprehensive Text with Models, Applications, References and DEA-Solver Software. Boston: Kluwer Academic Publishers.

Fare R, Grosskopf S, 2004. Modeling undesirable factors in efficiency evaluation. European Journal of Operational Research, 157(1): 242-251. doi: 10.1016/S0377-2217(03)00191-7

Fare R, Grosskopf S, Parurka C A, 2007. Environmental production functions and environmental directional distance functions: A joint production comparison. Energy, 32(7): 10551066. doi: 10.1016/j.energy.2006.09.005

Fischer-Kowalski M, Haberl H, 1997. Tons, joules, and money: Modes of production and their sustainability problems. Society \& Natural Resources, 10(1): 61-85. doi: 10.1080/0894192970 9381009

Forkes J, 2007. Nitrogen balance for the urban food metabolism of Toronto, Canada. Resources, Conservation and Recycling, 52(1): 74-94. doi: 10.1016/j.resconrec.2007.02.003 
Hammer M, Giljum S, Hinterberger F, 2003. Material flow analysis of the city of Hamburg. Paper Presented at the Workshop Quo vadis MFA? Material Flow Analysis-Where Do We Go? Issues, Trends and Perspectives of Research for Sustainable Resource Use, Wuppertal.

Halla R S, Shauna D, Christopher A K, 2003. Estimating the urban metabolism of Canadian cities. Canadian Journal of Civil Engineering, 30(2): 468-483. doi: 10.1139/102-105

Hendriks C, Obernosterer R, M"uller D et al., 2000. Material flow analysis: A tool to support environmental policy decision making - Case studies on the city of Vienna and the Swiss lowlands. Local Environment, 5(3): 311-328. doi: 10.1080/ 13549830050134257

Huang S L, 1998. Urban ecosystems, energetic hierarchies and ecological economics of Taipei metropolis. Journal of Environmental Management, 52 (1): 39-51. doi:10.1006/jema. 1997.0157

Huang S L, Hsu W L, 2003. Materials flow analysis and emergy evaluation of Taipei's urban construction. Landscape and Urban Planning, 63(2): 61-75. doi: 10.1016/S0169-2046(02) 00152-4

Huang S L, Chen C W, 2005. Theory of urban energetics and mechanisms of urban development. Ecology Model, 189(1-2): 49-71. doi: 10.1016/j.ecolmodel.2005.03.004

Huang S L, Lee C L, Chen C W, 2006. Socioeconomic metabolism in Taiwan: Emergy synthesis versus material flow analysis. Resources, Conservation and Recycling, 48: 166-196. doi: 10.1016/j.resconrec.2006.01.005

Jiang M M, Chen B, Zhou J B et al., 2007. Emergy account for biomass resource exploitation by agriculture in China. Energy Policy, 35(9): 4704-4719. doi: 10.1016/j.enpol.2007.03.014

Kennedy C, Cuddihy J, Engel-Yan J, 2007. The Changing Metabolism of Cities. Journal of Industrial Ecology, 11(2): 43-59. doi: $10.1162 /$ jie. 2007.1107

Lan S F, Odum H T, 1994. Emergy evaluation of the environment and economy of Hongkong. Journal of Environmental Science, 6(4): 432-449.

Lei K P, Wang Z S, 2008. Emergy synthesis of tourism-based urban ecosystem. Journal of Environmental Management, 88(4): 831-844. doi: 10.1016/j.jenvman.2007.04.009

Li L B, Hu J L, 2012. Ecological total-factor energy efficiency of regions in China. Energy Policy, 46: 216-224. doi: 10.1016/ j.enpol.2012.03.053

Lu H F, Ye Z, Zhao X F et al., 2003. A new emergy index for urban sustainable development. Acta ecologica sinica, 23(7): 1363-1368.

Mandal S K, Madheswaran S, 2010. Environmental efficiency of the Indian cement industry: An interstate analysis. Energy Policy, 38(2): 1108-1118. doi: 10.1016/j.enpol.2009.10.063

Newman P W G, Birrel R, Holmes D, 1996. Human Settlements in State of the Environment Australia. Australia: State of the Environment Advisory Council. Melbourne: CSIRO Publishing.

Newman P W G, 1999. Sustainability and cities: Extending the metabolism model. Land Use and Urban Planning, 44(4): 219-226. doi: 10.1016/S0169-2046(99)00009-2
National Bureau of Statistics of China, 2001-2011. China Statistical Yearbook 2001-2011. Beijing: China Statistics Press. (in Chinese)

National Bureau of Statistics of China, 2001-2011. China Urban Statistical Yearbook 2001-2011. Beijing: China Statistics Press. (in Chinese)

National Bureau of Statistics of China, 2001-2011. China Energy Statistical Yearbook 2001-2011. Beijing: China Statistics Press. (in Chinese)

National Bureau of Statistics of China, 2001-2011. China Environmental Statistical Yearbook 2001-2011. Beijing: China Statistics Press. (in Chinese)

Odum H T, 1988. Self-organization, transformity, and information. Science, 242(11): 1132-1139.

Odum H T, 1971. Environment, Power, and Society. New York: Wiley-Interscience.

Odum H T, 1996. Environmental Accounting-Emergy and Environmental Decision Making. New York: Wiley.

Odum H T, Brown M T, Brandt-Williams S, 2000. Introduction and Global Budget (Folio\#1). In: Handbook of emergy evaluation Florida Center for Environmental Policy. Gainesville: University of Florida.

Oggioni G, Riccardi R, Toninelli R, 2011. Eco-efficiency of the world cement industry: A data envelopment analysis. Energy Policy, 39(5): 2842-2854. doi: 10.1016/j.enpol.2011.02.057

Peng Jian, Wang Yanglin, Wu Jiangsheng et al., 2011. Research progress on evaluation frameworks of regional ecological sustainability. Chinese Geographical Science, 21(4): 496-510. doi: 10.1007/s11769-011-0490-0

Rotmans J, Van-Asselt M B, Vellinga P, 2000. An integrated planning tool for sustainable cities. Environmental Impact Assessment Review, 20(3): 265-276. doi: 10.1016/S0195-9255 (00)00039-1

Sahely H R, Dudding S, Kennedy C A, 2003. Estimating the urban metabolism of Canadian cities: Greater Toronto Area case study. Canadian Journal of Civil Engineering, 30(2): 83-468. doi: 10.1139/102-105

Selden T M, Song D, 1994. Environmental quality and development: Is there a Kuznets curve for air pollution emissions. Journal of Environmental Economics and Management, 27(2): 147-162. doi: 10.1006/jeem.1994.1031

Statistical Bureau of Beijing, 2001-2011. Beijing Statistical Yearbook 2001-2011. Beijing: China Statistics Press. (in Chinese)

Su M R, 2010. Emergy-based urban ecosystem health evaluation of the Yangtze River Delta urban cluster in China. Procedia Environmental Sciences, 2: 689-695. doi: 10.1016/j.proenv. 2010.10.078

Tone K, 2001. A slacks-based measure of efficiency in data envelopment analysis. European Journal of Operational Research, 130(3): 498-509. doi: 10.1016/S0377-2217(99)00407-5

Tone K, 2004. Dealing with undesirable outputs in DEA: A slacksbased measure (SBM) approach. Presentation at NAPWIII, Toronto.

Ulgiati S, Brown M T, 2009. Emergy and ecosystem complexity. 
Communications in Nonlinear Science and Numerical Simulation, 14(1): 310-321. doi: 10.1016/j.cnsns.2007.05.028

Wolman A, 1965. The metabolism of the city. Scientific American, 213(3): 179-190.

Zhang Y, Yang Z F, Li W, 2006a. Analyses of urban ecosystem based on information entropy. Ecological Modelling, 197(1-2): 1-12. doi: 10.1016/j.ecolmodel.2006.02.032

Zhang Y, Yang Z, Yu X, 2006b. Measurement and evaluation of interactions in complex urban ecosystem. Ecological Modeling, 196(1-2): 77-89. doi: 10.1016/j.ecolmodel.2006.02.001

Zhang Y, Yang Z F, 2007a. Emergy analysis of urban material metabolism and evaluation of eco-efficiency in Beijing. ACTA Scientiae Circumstantiae, 27 (11): 1892-1900. (in Chinese)

Zhang Y, Yang Z F, 2007b. Eco-efficiency of urban material metabolism: A case study in Shenzhen, China. Acta Ecologica Sinica, 27(8): 3124-3131. doi: 10.1016/S1872-2032(07)60067-5

Zhang Y, Yang Z F, Yu X Y, 2009. Evaluation of urban metabo- lism based on emergy synthesis: A case study for Beijing (China). Ecological Modelling, 220(13-14): 1690-1696. doi: 10.1016/j.ecolmodel.2009.04.002

Zhang Y, Yang Z, Liu G et al., 2011. Emergy analysis of the urban metabolism of Beijing. Ecological Modelling, 222(14): 2377-2384. doi: 10.1016/j.ecolmodel.2010.09.017

Zhou P, Ang B W, Poh K L, 2006. Slacks-based efficiency measures for modeling environmental performance. Ecological Economics, 60(1): 111-118. doi: 10.1016/j.ecolecon.2005.12.001

Zhou P, Ang B W, Poh K L, 2008. A survey of data envelopment analysis in energy and environmental studies. European Journal of Operational Research, 189(1): 1-18. doi: 10.1016/j. ejor.2007.04.042

Zhou Y, Xing X P, Fang K N et al., 2013. Environmental efficiency analysis of power industry in China based on an entropy SBM model. Energy Policy, 57(6): 68-75. doi: 10.1016/ j.enpol.2012.09.060 